\title{
Exploring the business of urology: Is it time for a "Business of Healthcare" curriculum in urology residency programs?
}

\author{
Darren Beiko, MD, MBA, FRCSC'; Christopher M. Gonzalez, MD, MBA'; Arthur P. Mourtzinos, MD, MBA'; \\ Eugene Y. Rhee, $M D, M B A^{4}$
}

'Department of Urology, Queen's University, Kingston, ON; ${ }^{2}$ Urology Institute, University Hospitals Cleveland Medical Center, Case Western Reserve Medical School, Cleveland, OH; ${ }^{3}$ Institute of Urology, Lahey Hospital and Medical Center, Burlington, MA; ${ }^{4}$ Department of Urology, Southern California Kaiser Permanente Medical Group, San Diego, CA

Cite as: Can Urol Assoc J 2018;12(10):299-300. hitp://dx.doi.org/10.5489/cuaj.5573

U rology is a relatively small surgical specialty filled with innovative and forward-thinking physicians. Decade after decade, through early adoption of new technologies, urologists have been at the cutting edge of advances in medical and surgical care. Urologists are generally very well-prepared for the rapidly evolving improvements medical and surgical technology. But are graduating urologists prepared for the business side of their practices and careers? After completion of postgraduate training and upon entry into the workforce, are most urologists prepared for the multiple roles and demands that will be placed upon them in today's dynamic healthcare environment? Does residency provide adequate education and evalution of basic business topics and principles that are critical to achieving high performance in one's job as a urologist? Do we adequately train urologists to manage all aspects of the operations of their own practice, including the negotiation and legal execution of employment agreements and contracts? Are urologists adequately prepared to navigate the Canadian and U.S. healthcare landscapes and trends in the delivery of care? Unfortunately, the answer to these questions for most young urologists is, "No."

Healthcare costs around the world have become unsustainable. Healthcare spending accounted for an average of $9.0 \%$ of gross domestic product (GDP) across the Organization for Economic Co-operation and Development (OECD) countries in 2016, and an astonishing $17.2 \%$ of GDP in the U.S. ${ }^{1}$ In Canada, healthcare accounts for the largest percentage of provincial and territorial budgets. ${ }^{2}$ Today, most Canadians recognize that our provincial and territorial healthcare systems are not financially sustainable. In the business world and in healthcare, value is defined as quality divided by cost. ${ }^{3}$ Therefore, in order to deliver the greatest possible healthcare value to North Americans, our overriding goals need to be focused on increasing quality of care while reducing the cost of delivering that very same high-quality care. In order to achieve these goals, North American healthcare systems are in need of future physican healthcare leaders who are properly educated in both medicine and business. Current literature suggests that physicians in general want and need more training in basic business principles. ${ }^{4} \mathrm{~A}$ few medical and surgical specialties have attempted to address this issue by incorporating single or limited courses on topics such as leadership or general management. ${ }^{5-8}$ Although there is some evidence that a web-based curriculum improves the business knowledge of residents, ${ }^{9}$ to date, a proper needs assessment - what specifically such a curriculum should look like and how to best deliver it - has not been completed.

Currently, most, if not all, North American urology residency programs have inadequate exposure to and teaching of basic business principles, including topics typically taught in in Master of Business Administration (MBA) programs. There are several Medical Doctor/MBA (MD/MBA) programs in North America, however, a formal MBA for all MDs is unnecessary and impractical. A sound argument could be made for the teaching of business principles during residency as opposed to medical school, closer to when the physician is about to go into practice. After all, this is when young physicians will most require sound business and administration principles in order to succeed. Additionally, it is during residency that the majority of exposure to and teaching of CanMEDS roles takes place, and it is easy to appreciate the overlap between some of the potential business topics to teach and some of the non-medical expert CanMEDS roles.

Specific business topics to consider are shown in Fig. 1. A "Business of Healthcare" curriculum would equip graduates of North American urology residency programs with the necessary tools to perform at a high level in their various future clinical and administrative roles, along with possible research and education roles. For example, basic training on how to negotiate is just one example that highlights the value of such a curriculum; negotiation is a skill that most urologists use on a daily basis in a number of different contexts. Application of basic principles in business administration could profoundly affect how future urologists interact with patients, the general public, their colleagues, students, and other members of the healthcare profession. Optimal interaction with other healthcare professionals is becoming increasingly important, given the recent shift toward a col- 


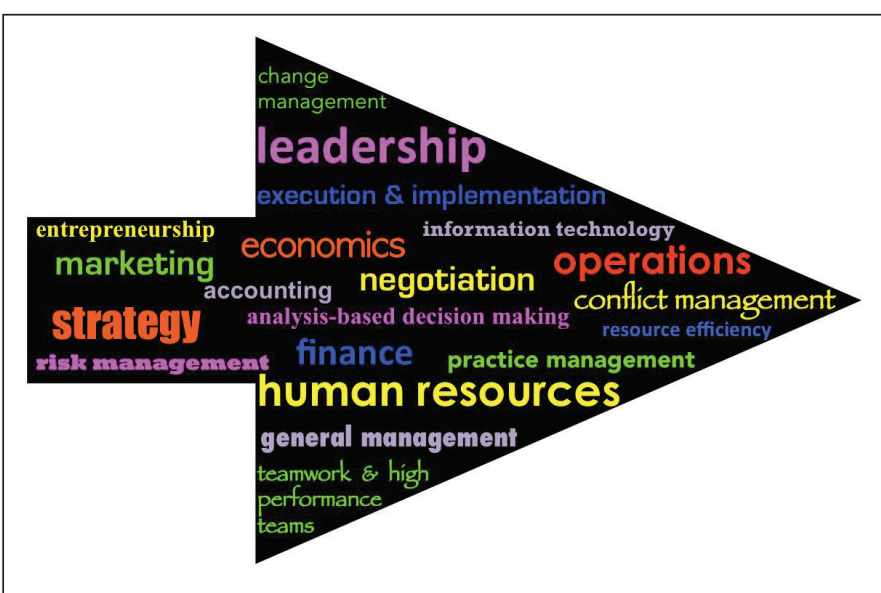

Fig. 1. Potential topics to be considered for a "Business of Healthcare" curriculum.

laborative care practice model in the delivery of healthcare. More than ever, it is crucial that urologists of the next generation remain forward-thinking by receiving some formal training and education in business administration principles.

Unquestionably, there exist potential barriers to a "Business of Healthcare" curriculum. When planning and implementing any new curriculum, there are several anticipated challenges and barriers to overcome. Specific unanswered questions would first need to be addressed. Is there an adequate appetite for a "Business of Healthcare" curriculum? How would the curriculum be funded? Can we reach consensus on which specific topics to include? Should the curriculum be delivered locally or nationally? Should the teaching occur horizontally during residency or vertically as a weekend or week-long course? Can suitable local or national educators be identified, and if so, will they commit to the daunting task of creating a curriculum, working out the logistics, and ultimately teaching the material? When is the optimal time to deliver such a curriculum?

Due to the demands of training of clinical urology during residency, perhaps residency is not the optimal time for business and management training. Some may argue that practicing physicians have a better perspective on healthcare issues on both the macro and micro levels, making them better suited for formal or informal business training. After practicing medicine for a few years, urologists may better understand the "translational" aspect of business principles to everyday healthcare challenges, such as medical supply and inventory management, lean operations and throughput, leadership, negotiation, marketing, and finance. Urology leaders may not agree on the optimal timing of business education, but once in practice, there never seems to be optimal timing for most things. And since residency provides reliable and structured education, we think it would be easier to achieve universal business education for future urologists by incorporating such a program into residencies.
Moving forward, a logical starting point would be to complete a needs assessment study of urologists and urology residents to identify gaps and opportunities in the teaching of basic business topics in North American urology residency programs. If the needs assessment study supports the need for such a curriculum, the ultimate objectives would shift to: 1 ) developing the content and structure for an innovative "Business of Healthcare" curriculum that could be incorporated into urology residency programs across North America; and 2) widely disseminating the findings of a needs assessment study across other medical and surgical specialties. And if such a curriculum could be developed, urology could serve as a model for other specialties. Furthermore, urology's "Business of Healthcare" curriculum could potentially serve as a pilot specialty for the Royal College of Physicians and Surgeons of Canada (RCPSC) and the Accreditation Council for Graduate Medical Education (ACGME).

We think it's time for a "Business of Healthcare" curriculum in urology residency programs, and we urge the innovative and forward-thinking educational leaders in our small specialty to address this deficiency in the training and education of urologists.

Competing interests: The authors report no competing personal or financial interests.

This paper has been peer-reviewed.

\section{References}

1. OECD Health Statistics 2014. Available at hittp://stats.oecd.org/index.aspx?DataSetCode=HEALTH_STAT. Accessed Feb. 5, 2018.

2. Drummond D, Giroux D, PigottS, et al. Commission on the reform of Ontario public service. 2012. Available at http://www.fin.gov.on.ca/en/reformcommission/chapters/report.pdf. Accessed March 10, 2015.

3. Kogan BA. The importance of quantifying value. Can Urol Assoc J 2013;7:99. hitps://doi.org/10.5489/ cuaj.701

4. Hill AD. Improving business IQ in medicine through mentorship and education. J Orthop Trauma 2014;28 Suppl 9:S9.https://doi.org/10.1097/BOT.0000000000000177

5. Gunderman RB, Tawadros AM. Business education for radiology residents: The value of full-time business educators. Acad Radiol 2011;18:645. https://doi.org/10.1016/j.acra.2010.11.021

6. Bayard $M$, Peeples $C R$, Holt J et al. An interactive approach to teaching practice management to family practice residents. Fam Med 2003;35:622.

7. Falvo T, McKniff $S$, Smolin $G$ et al. The business of emergency medicine: A non-clinical curriculum proposal for emergency medicine residency programs. Acad Emerg Med 2009;16:900. https://doi.org/10.1111/i.1553-2712.2009.00506.x

8. Desai AM, Trillo RA Jr, Macario A. Should I get a Master of Business Administration? The anesthesiologist with education training: Training options and professional opportunities. Curr Opin Anaesthesiol 2009;22:191. https://doi.org/10.1097/AC0.0b013e3283232c4e

9. Hauge $L S$, Frischknecht $A C$, Gauger $P G$ et al. Web-based curriculum improves residents' knowledge of health care business. J Am Coll Surg 2010;211:777. https://doi.org/10.1016/i.jamcollsurg.2010.07.011

Correspondence: Dr. Darren Beiko, Department of Urology, Queen's University, Kingston, ON, Canada; darren.beiko@kingstonhsc.ca 